\title{
Development of UV Protective Clothing for College Going Girls
}

\author{
Beenu Singh*, Manisha Gahlot and Anita Rani \\ Department of Clothing and Textiles, College of Home Science, G. B. Pant University of \\ Agriculture and Technology Pantnagar, U. S. Nagar, Uttarakhand, India \\ *Corresponding author
}

\section{Keywords}

UV radiation, Sunburn, Tanning, UV Protective Clothing, UPF

Article Info

Accepted:

12 May 2019

Available Online:

10 June 2019

\section{A B S T R A C T}

An increase in outdoor activities and habits of human frequently result in more exposure to UV radiation of sun. UV radiation is a known carcinogen and also responsible for sunburn and tanning. Different protective measures such as sunscreen lotions and protective clothing/accessories are being used for protection against harmful UV effects of sunlight. Sunscreen gives protection for a certain period of time therefore sun-protective clothing is the single most effective way to protect oneself from the harmful UV rays for a long time. The clothing items for sun protection available in the market and online shopping web portals are not trendy and cost effective. Therefore, the study was conducted to develop such products that are trendy, cost effective, comfortable, easy to wear and designed from fabrics having desirable properties required for UV protection. The four different styles (shirt, shrug, mask with cap and scarf based) of sun protective clothing (two each) were designed and constructed. Suitability of protective clothing was assessed on the basis of structural features, aesthetic features and functional features by wear trial. All the items were highly appreciated by the respondents for the intended use.

\section{Introduction}

Sunlight is comprised of different wavelengths which spread across the electromagnetic spectrum. Few of these wavelengths are filtered on passing through the earth's atmosphere but left behind radiation which reaches the earth in the form of ultraviolet (UV), visible and infrared light (IR). Among these radiations, UV rays are of specific concern because it can contact with skin cells and cause a variety of harmful effects ${ }^{1}$. Prolonged human exposure to solar UV radiation may result in acute and chronic health effects on the skin, eye and immune system. Sunburn and tanning are the best known acute effects of excessive solar UV radiation exposure ${ }^{5}$.

Moreover the prevalence of skin cancer has been growing at very fast rate over past several years. The increment in outer activities like going out for job, enjoyment or work exposure to the sun has been a chief factor in the rising incidence of skin cancer. Precaution must be taken when exposed to these types of energy to protect and defend against long-lasting effects. Restricting the 
skin's exposure to sunlight, especially when the intensity is maximum, is the best way to reduce danger ${ }^{3}$. That can be done either with the application of sunscreen lotions or by covering the exposed parts of body with some fabric. But sunscreen gives protection for a certain period of time because after that it is no longer effective. It should then be reapplied from time to time as per the requirement.

Czajkowski and Paluszkiewicz (2008) stated that the clothing offers the safest protection from UV radiation (UVR) and its protective properties depend on fabric composition (natural or man-made fibers), specification of fabric (porosity, thickness and weight), dyeing (natural or synthetic dyes, UV absorbing properties, dye concentration etc).

The proper combination of mentioned factors allows production of woven fabrics withhigh UV protection properties, which may reduce risk associated with overexposure to sun.

Personal appearance is considered very important especially by women. Both good health and complexion of skin contribute to appearance. Teenage and young females are more conscious of their appearance than other age groups as they are influenced by fashion and media portrayals of attractiveness. Proper sun protection can also reduce the incidents of sunburn, skin irritation, and premature skin ageing. Hence, sun-protective clothing is the single most effective way to protect oneself from the harmful rays of the sun, even more than the use of sunscreen lotions ${ }^{4}$.

Market is also expected to benefit from the growing level of fashion consciousness among females. Because products available in the market and online websites mostly are not according to the current fashion, poor in fabric quality, functional utility, do not able to give full protection and are not cost effective as youth are having limited amount in their hands to spend on such products. Therefore, the present study was conducted to develop such products which are trendy, cost effective, comfortable, and easy to wear and designed from fabrics having desirable properties which are required for protection against the ultraviolet radiations of sun.

\section{Materials and Methods}

\section{Preference of respondents for the features in textile based sun protective items}

Data was collected from the female respondents regarding the preference for the features in textile based sun protective products. Total sixty students (U.G, P.G, Ph.D. students of GBPUA\&T Pantnagar) were selected. Fabric samples collected from the local market were shown to the respondents. Their choices were noted for fabric type, colour and pattern for development of sun protective clothing. The respondents were also asked about their choice for type of fasteners, style of garment and type of features which should be taken into consideration while designing and development of sun protective clothing.

\section{Designing of protective clothing and construction of muslin prototypes}

Designing of four categories i.e. shirt style, shrug style, scarf style, mask with cap style each category were developed in the study (Figure $1 \mathrm{a}, \mathrm{b}, \mathrm{c}, \mathrm{d}$ ).

Muslin prototypes were developed to check the actual fall and drape of the eight sketched designs. The prototypes were drafted and constructed in muslin fabric for evaluation. Measurements and drafting were done according to the system given by Zarapkar (1999) using standard inch tape. Paper patterns were cut on brown paper with seam 
allowance and placed on the fabric for cutting and stitched on the simple stitching machine. The four designs were selected after evaluation by a panel of 30 respondents consisting of staff members, Ph.D. and M.Sc. students from Department. Wear trial of constructed sun protected garments was done on 20 respondents.

Assessment of physical properties of fabrics

Fabrics used for construction of protective clothing were tested for different fabric properties such as fabric thickness, thread count and GSM according to the standard procedures. These fabric properties have direct and significant effect on UPF. Hence only these properties of fabric were tested.

Assessment of Ultraviolet Protection Factor (UPF) (AATCC - 183: 2004)

UPF of fabric samples was determined by using "SDL UV penetration and protection measurement system (Compsec M350 UVVisible spectrometer)" according to test method given in UVR TRANSMISSION by AATCC.

\section{Results and Discussion}

Preference of respondents for the features in textile based sun protective items

Preference of respondents was noted for fabric type, colour and pattern, type of fasteners, style of garment and the type of functional features for development of sun protective clothing.

\section{Fabric preferred}

Three types of fabric samples (cotton, rayon, synthetic and blended fabric) were shown to the respondents. It can be visualized from the data given in Table 1 that most of the respondents $(63.33 \%)$ preferred cotton material followed by rayon $(35 \%)$ and blended fabric $(1.66 \%)$.

\section{Preference for colour and pattern of fabric}

The data in Table 1 reveals that maximum number of the respondents $(35 \%)$ preferred medium colour fabric followed by light colour $(33.33 \%)$ and dark colour $(31.66 \%)$. The majority of the respondents $(96.66 \%)$ liked printed fabric while only $3.33 \%$ liked solid pattern.

\section{Preference for style or design of protective clothing}

Images of different sun protective clothing items were shown to respondents. Images comprised of four different styles namely cap/hat based, shirt based, shrug based and scarf based. It can be visualized from Table 1 that $30 \%$ of the respondents liked shrug based design, followed by $25 \%$ who preferred scarf based design. Percentage of respondents who gave their choice for shirt and cap/hat based designs were $23.33 \%$ and $21.66 \%$, respectively.

\section{Preference for the features in the product}

During interview it was observed that all the respondents showed their preference for all the features which should be present in the protective clothing. Hence they were asked to give their top preference and data presented in the Table 1 depicts that more than half of the respondents $(51.66 \%)$ preferred features like easy to use followed by $30 \%$ respondents who preferred easy to carry feature in protective clothing.

While $11.66 \%$ and $6.66 \%$ respondents showed their preference for features like easy folding and less wrinkling respectively. 
Table.1 Preference for the characteristics in the fabric based sun protection measures

\begin{tabular}{|c|c|c|c|c|}
\hline Sl. No. & & & Frequency & Percentage \\
\hline \multirow[t]{3}{*}{1} & \multirow[t]{3}{*}{ Types of fabrics } & Cotton & 38 & 63.33 \\
\hline & & Rayon & 21 & 35.00 \\
\hline & & Blended & 1 & 1.66 \\
\hline \multirow[t]{3}{*}{2} & \multirow[t]{3}{*}{ Colour } & Light & 20 & 33.33 \\
\hline & & Medium & 21 & 35.00 \\
\hline & & Dark & 19 & 31.66 \\
\hline \multirow[t]{2}{*}{3} & \multirow[t]{2}{*}{ Pattern } & Printed & 58 & 96.66 \\
\hline & & Solid & 2 & 3.33 \\
\hline \multirow[t]{4}{*}{4} & \multirow[t]{4}{*}{ Different styles } & Cap/ hat based & 13 & 21.66 \\
\hline & & Shirt based & 14 & 23.33 \\
\hline & & Shrug based & 18 & 30.00 \\
\hline & & Scarf based & 15 & 25.00 \\
\hline \multirow[t]{4}{*}{5} & \multirow[t]{4}{*}{ Features } & Wrinkle less & 4 & 6.66 \\
\hline & & Easy folding & 7 & 11.66 \\
\hline & & East to carry & 18 & 30.00 \\
\hline & & Easy to use & 31 & 51.66 \\
\hline \multirow[t]{5}{*}{6} & \multirow[t]{5}{*}{ Types of fasteners } & Button/ Button hole & 11 & 18.33 \\
\hline & & Press button & 8 & 13.33 \\
\hline & & Velcro & 22 & 36.66 \\
\hline & & String & 12 & 20 \\
\hline & & Belt & 7 & 11.66 \\
\hline
\end{tabular}

Table.2 Assessment of designs developed for sun protective clothing

\begin{tabular}{|c|c|c|}
\hline SI. No. & Type of protective clothing & WMS \\
\hline $\mathbf{1}$ & Shirt style (Arm cover) & 4.17 \\
\hline & Design 1 & 4.29 \\
\hline & Design 2 & \\
\hline $\mathbf{2}$ & Shrug style (Arm cover) & 3.96 \\
\hline & Design 1 & 4.44 \\
\hline & Design 2 & \\
\hline $\mathbf{3}$ & Mask with cap style (Face and head cover) & 4.05 \\
\hline & Design 1 & 4.06 \\
\hline & Design 2 & 4.3 \\
\hline $\mathbf{4}$ & Scarf style (Face and head cover) & 4.03 \\
\hline
\end{tabular}


Table.3 Physical properties of selected fabric samples

\begin{tabular}{|c|c|c|c|}
\hline Sl. No. & Properties & Rayon fabric & Cotton fabric \\
\hline $\mathbf{1}$ & Fabric count $($ ends $\times$ picks) & $84 \times 64$ & $147 \times 139$ \\
\hline $\mathbf{2}$ & Fabric thickness $(\mathrm{mm})$ & 0.29 & 0.22 \\
\hline $\mathbf{3}$ & Weight per unit area $\left(\mathrm{g} / \mathrm{m}^{2}\right)$ & 107.80 & 110.36 \\
\hline $\mathbf{4}$ & Ultraviolet Protection Factor $(\mathrm{UPF})$ & 13.9 & 70.8 \\
\hline
\end{tabular}

Table.4 Assessment of the Suitability of Designed and Developed Protective Clothing

\begin{tabular}{|c|c|c|c|}
\hline Sl. No. & Type of protective clothing & Features of garment & WMS \\
\hline \multirow[t]{3}{*}{1} & \multirow[t]{3}{*}{ Sun protective shirt } & Structural features & 4.6 \\
\hline & & Aesthetic features (Fabric) & 4.7 \\
\hline & & Functional features & 4.9 \\
\hline \multirow[t]{3}{*}{2} & \multirow[t]{3}{*}{ Sun protective shrug } & Structural features & 4.7 \\
\hline & & Aesthetic features (Fabric) & 4.6 \\
\hline & & Functional features & 4.8 \\
\hline \multirow[t]{3}{*}{3} & \multirow[t]{3}{*}{ Sun protective mask with cap } & Structural features & 4.9 \\
\hline & & Aesthetic features (Fabric) & 4.6 \\
\hline & & Functional features & 4.9 \\
\hline \multirow[t]{3}{*}{4} & \multirow[t]{3}{*}{ Sun protective scarf } & Structural features & 4.7 \\
\hline & & Aesthetic features (Fabric) & 4.9 \\
\hline & & Functional features & 4.8 \\
\hline
\end{tabular}

Fig.1 Designing of UV protective clothing. (a) Shirt style (b) Shrug style (c) Mask with cap style (d) Scarf style

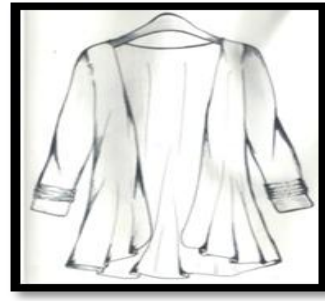

Design 1

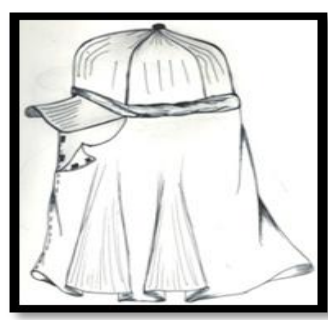

Design 1

(c)

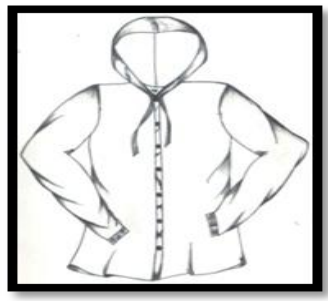

(a) Design 2

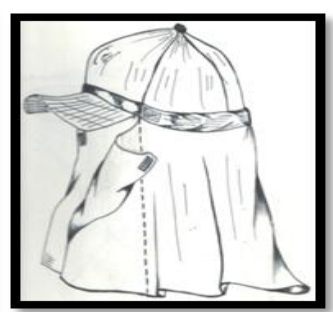

Design 2
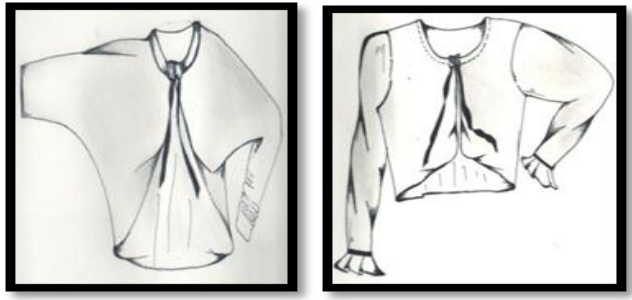

(b)

Design 2
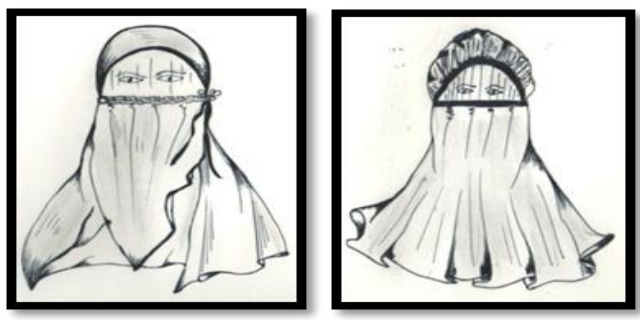

Design 1

(d) Design 2 
Fig.2 Developed products: Sun protected shirt (a) Sun protected shrug (b) Sun protected mask with cap (c) Sun protected scarf (d)

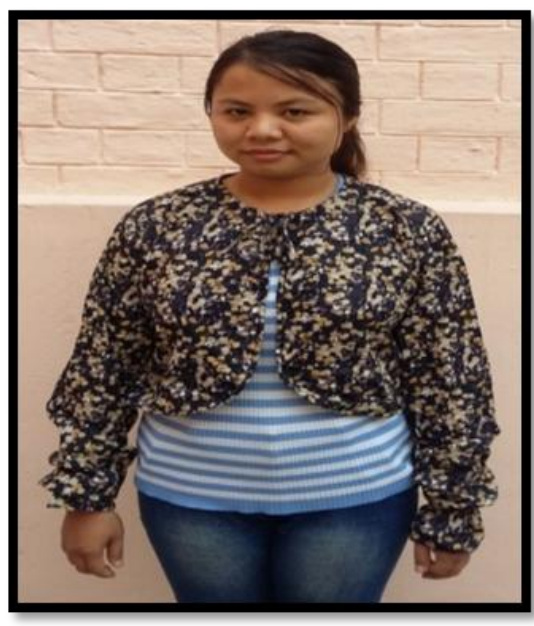

(a)

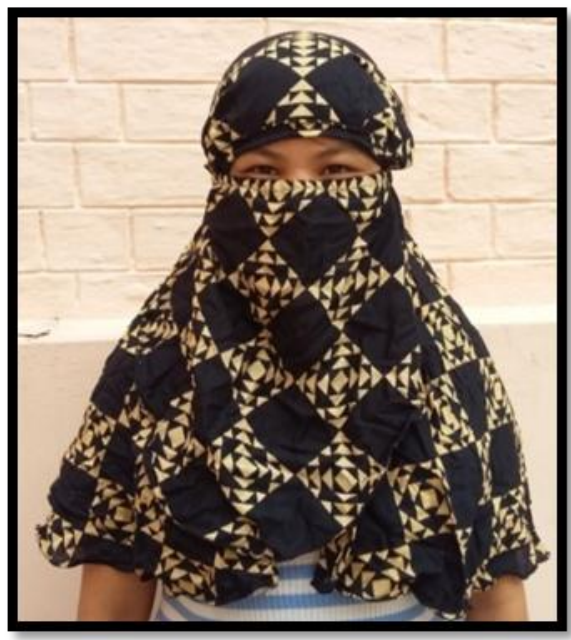

(c)

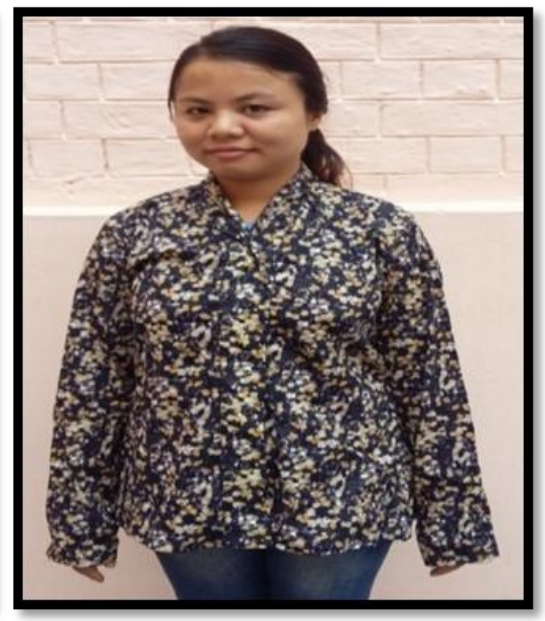

(b)

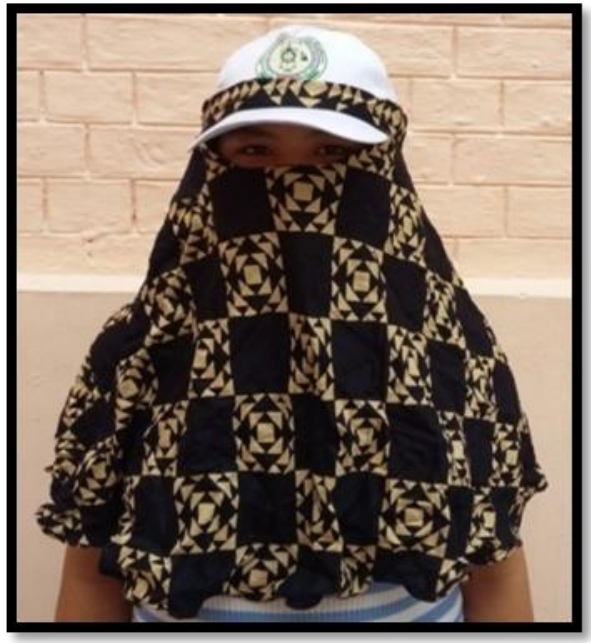

(d)
Preference for the fasteners to be used in products

The data in Table 1 reveals that most of the respondents $(36.66 \%)$ liked velcro as they found it easy to use, followed by string (20\%), button/button hole $(18.33 \%)$, press buttons (13.33\%) and belt (11.66\%).

\section{Assessment of designs developed for sun protective clothing}

The developed designs were evaluated by a panel of respondents consisting of M.Sc.,
Ph.D. and faculty members of Clothing and Textiles Department on five point rating scale and WMS (Weighted mean score) was calculated.

The results obtained from the evaluation of four categories of designs i.e., shirt, shrug, scarf and cap are given in Table 2 .

The design no. 2 of shirt style, shrug style and mask with cap style and design no. 1 in scarf style was selected based on more WMS (Table 2). 
Physical properties of fabric used for construction of sun protective clothing

Printed fabrics of cotton and rayon were selected for the construction of sun protective clothing based on the preference given by the respondents in medium to dark colour (Table $3)$. Hence these fabrics were tested for different fabric properties such as fabric count, fabric thickness and weight per unit area which have direct and significant effect on UPF. It is clear from Table 3 that rayon fabric had 84 ends and 64 picks per square inch while cotton fabric had 147 ends and 139 picks per square inch. Thickness values given in Table 3 indicate that rayon fabric had more thickness i.e. $0.29 \mathrm{~mm}$ as compared to cotton fabric with thickness of $0.22 \mathrm{~mm}$. The cotton fabric had more weight i.e. $110.36 \mathrm{~g} / \mathrm{m}^{2}$ as compared to rayon fabric with weight of $107.80 \mathrm{~g} / \mathrm{m}^{2}$. UPF of cotton fabric was found to be 70.8 which mean excellent protection, while UPF of rayon was only 13.9 (i.e. less than 15).

\section{Assessment of the suitability of designed and developed protective clothing}

Four different type of sun protective clothing were constructed in the present study (Figure 2). Suitability of these constructed products was assessed by wear trial on 20 respondents. Five respondents were selected for each product. Respondents covered approximate distance of $4-5 \mathrm{~km}$ per day either by bicycle or by walking. They used to travel between college and hostel in the forenoons and afternoons for classes and research work at least four times a day in summers (May). The main function of sun protective clothing was to provide protection from the sun along with comfort aspect and aesthetic appeal as it was meant for college going girls. Different features of the garments like structural features, aesthetic features and functional features were assessed using five point rating scale and weighted mean score was calculated for each parameter. Suitability assessment of developed sun protective shirt, shrug, mask with cap and scarf mask is given in Table 4 . Average WMS of shirt and shrug was 4.7 whereas mask with cap and scarf obtained 4.8 WMS.

In conclusion, tanning is the common phenomenon which is observed by most of the people on exposure to sunlight with the noticeable effect. Developed sun protective clothing items were found to be highly suitable and acceptable by the respondents because of the protective features, comfort and ease of use during wear due to the constructional features. Appropriate selection of fabric, its colour and print made the developed clothing trendy which was also acknowledged by the respondents during wear trial. Therefore, these textiles based sun protection products are very important that are developed for the college and office going females who used to travel by cycle or two wheelers. It can also be envisioned that there is more scope as well as more need, in the field of designing and development of sun protective clothing using different type of fabric and styles.

\section{References}

Christ, R., and Piwowar-Baryłko, U. 1995. Sun protection in cosmetics. PollenaTtuszcze, S'rodkiPioracce, Kosmetyki, 39(9):349-354.

Czajkowski, W. and Paluszkiewicz, J. 2008. Synthesis of Bifunctional Monochlorotriazine Reactive Dyes Increasing UV-Protection Properties of Cotton Fabrics. Fibers and Textiles in Eastern Europe January, 5(70):122-26.

Pailthorpe, M. T. and Chriskis, J. I. 1995. Sun protection of apparel Materials. Dermatolologic Clinics, 24 (1): 85-100.

Wilson, Cheryl A. (2015). Maximising 
protection - Sun protective fabric and clothing. Dunedin, New Zealand: University of Otago. Retrieved September, 26, 2015 from www.otago.ac.nz/textile.

Yallambie, V. 2003. Resource Guide for UV Protective Products 2003 - Information Section, Australian Radiation Protection and Nuclear Safety Agency, accessible at http:// www.apparel.ca/_static/ webupload/ website Documents/ 100000/UV\%20r.

Zarapkar. 1999. System of Cutting. Gujarat, Navneet Publications Limited.

\section{How to cite this article:}

Beenu Singh, Manisha Gahlot and Anita Rani. 2019. Development of UV Protective Clothing for College Going Girls. Int.J.Curr.Microbiol.App.Sci. 8(06): 1614-1621.

doi: https://doi.org/10.20546/ijcmas.2019.806.194 